\title{
A importância do Programa de Residência Pedagógica na formação de professores no Instituto Federal Farroupilha- Campus São Vicente do Sul
}

\section{The importance of the Pedagogical Residency Program in the Teacher Training at the Federal Institute Farroupilha-Campus São Vicente do Sul}

Eliane Barcelos Santos (elianebarcelos.ebs@gmail.com) (Instituto Federal Farroupilha- campus São Vicente do Sul)

Mirieli da Silva Martins (miriellismartinss@gmail.com) (Instituto Federal Farroupilha- campus São Vicente do Sul)

\section{Maria Rosângela Silveira Ramos (maria.ramos@iffarroupilha.edu.br)} (Instituto Federal Farroupilha- campus São Vicente do Sul)]

Catiane Mazocco Paniz (catiane.paniz@iffarroupilha.edu.br) (Instituto Federal Farroupilha- campus São Vicente do Sul)

Helena Brum Neto (helena.neto@iffarroupilha.edu.br) (Instituto Federal Farroupilha- campus São Vicente do Sul)

\section{Resumo:}

O presente estudo tem como foco central abordar o Programa Multidisciplinar de Residência Pedagógica (RP) considerando sua relevância no processo de formação inicial ao propor uma investigação sobre a percepção dos residentes dos cursos de Licenciaturas em Ciências Biológicas e Química do Instituto Federal Farroupilha, Campus São Vicente do Sul (IFFar-SVS), possuem a respeito da RP, para sua formação inicial. A metodologia utilizada foi quantiqualitativa, utilizando-se de referenciais teóricos pertinentes ao tema proposto e um instrumento de pesquisa para coleta de dados, no intuito de identificar e compreender a importância da RP para a formação docente, bem como, a validade das experiências construídas no Programa. Os resultados convergem para experiências construtivas no e para o saber/ fazer docente, demonstrando que a RP é uma experiência concreta e válida na e para a formação de professores. Nesse sentido, o programa contribui de forma efetiva para unir teoria e prática, suprindo algumas lacunas que persistem no curso de licenciatura. Na pesquisa ficou evidenciado pelos residentes que os objetivos estabelecidos pelo Programa estão sendo alcançados, portanto, ofertando a formação de professores mais complexa, propondo a vivência dentro do espaço escolar, possibilitando a troca de conhecimento entre os ambientes.

Palavras-chave: Políticas Educacionais; Prática Docente; Prática Pedagógica 


\begin{abstract}
:
This study is focused on approach the Multidisciplinary Pedagogical Residence Program (RP - Residência Pedagógica, in Portuguese) taking into account its relevance in the initial training process by proposing an investigation on the residents' RP perception in their initial training of the Biological Science and and Chemistry Degrees of the Federal Institute Farroupilha, at the São Vicente do Sul Campus (IFFar-SVS). The methodology used was quantitative-qualitative (or quantiqualitative), having pertinent theoretical approaches to the proposed investigation, and a research tool for data collection, in order to identify and understand the importance of RP for teacher's training, as well as the validity of the lived experiences in the Program. The obtained results converge to constructive experiences in/to the teacher's know-how, showing that RP is a factual and valid experience in/and for teacher training. In this sense, the Program effectively contributes to join theory and practice, filling some gaps that persist in the Degree course level. The research results from the residents clearly show that the objectives established by the Program are being achieved, thus offering the most complex teacher training, by proposing the experience within the school atmosphere, enabling the exchange of knowledge between the environments.
\end{abstract}

Keywords: Educational Policies; Teaching Practice; Pedagogical Practice

\title{
1. INTRODUÇÃO
}

Evidencia-se, atualmente, a preocupação com a formação de professores, políticas e programas que respaldam uma formação mais complexa no sentido de abarcar a relação sociedade e natureza contemporânea. No decorrer do processo formativo do professor tem-se momentos de experienciação e aprendizagens para que o licenciando construa uma identificação com a docência, e ao mesmo tempo, sinta-se pertinente na carreira escolhida.

Torna-se importante todo o tipo de experiência que o Curso de Licenciatura oferece para dessa forma contribuir na afirmativa da escolha de carreira. Nesse sentido, o Programa de Residência Pedagógica é uma das ações que integram a Política Nacional de Formação de Professores, as quais visam promover e aperfeiçoar a formação docente, propiciando aos licenciandos a inserção no ambiente escolar (BRASIL, 2018). Assim, entre outras atividades, regência de sala de aula e intervenção pedagógica, acompanhados por professores orientadores, intensificam a relação de teoria e prática, capacitando e preparando o estudante de licenciatura para o real contexto das escolas e salas de aulas. 
Além, da importância do acadêmico se identificar com a profissão docente é preciso que sua formação seja capaz de atender aos requisitos impostos a esses profissionais pela educação. O licenciando deve estar atento sobre as suas responsabilidades, uma vez, que educar é compartilhar saberes com crianças, jovens e adultos em uma sociedade complexa e em transformação diariamente.

Nesse contexto o estreitamento dos laços do licenciando com a realidade escolar, o Programa de RP é uma das políticas públicas que integram a Política Nacional de Formação de Professores, fomentada pela Coordenação de Aperfeiçoamento de Pessoal de Nível Superior (CAPES). Desse modo, as atividades propostas na RP, intensificam a relação de teoria e prática, capacitando e preparando o estudante de licenciatura para o real contexto das escolas e salas de aulas. Nesse sentido, destacamos os objetivos apresentados no referido programa:

(I) o aperfeiçoamento da formação dos discentes dos cursos de licenciatura, por meio das atividades propostas que possam fortalecer o campo da prática, utilizando coleta de dados e diagnósticos contribuindo para o ensino e a aprendizagem escolar;

(II) induzir a reformulação da formação prática nos cursos de licenciatura, tendo por base a experiência da Residência Pedagógica;

(III) fortalecer, ampliar e consolidar a relação entre a Instituição de Ensino Superior e a escola, promovendo sinergia entre a entidade que forma e a que recebe o egresso da licenciatura, intensificando o papel das redes de ensino na formação de professores;

(IV) por fim, promover a adequação dos currículos e propostas pedagógicas dos cursos de formação inicial de professores da educação básica às orientações da Base Nacional Comum Curricular (BRASIL, 2018, p. 1).

Buscando como premissas básicas, o entendimento de que, a formação de professores nos cursos de licenciatura deve assegurar aos seus egressos habilidades e competências que possam lhes permitir realizar um ensino de qualidade nas escolas de educação básica (BRASIL, 2018). Colaborando Pannuti (2015, p. 3), corrobora que,

Tendo em vista os desafios atuais impostos pela sociedade contemporânea, parece necessário ressaltar o papel da educação e professor, por essa razão torna-se plausível a importância de programas de formação de professores que contemplem, dentre outras, a criação de um espaço de formação diferenciado, que crie oportunidades para a troca de experiências entre os profissionais (PANNUTI, 2015, p. 3). 
Desse modo, o residente da RP, terá a possibilidade de adquirir, compartilhar e refletir sobre os saberes que vivencia durante sua trajetória acadêmica e enquanto componente desse Programa. Além disso, possui a oportunidade de adentrar ao cotidiano escolar como profissional da Educação, o que não é comum, nem ofertado somente pelos cursos formadores de professores, para tanto, tal integração é aliada para uma construção de saberes eficiente e completa. Nesse sentido, o programa da RP, oportuniza a formação inicial dos Residentes, com vivências diretas no locus escolar, bem como no exercício de práticas diversificadas. Assim,

\begin{abstract}
O programa de residência pedagógica vem buscando o aprimoramento da formação docente por meio da necessária articulação entre o que os alunos aprendem na universidade e o que experimentam na prática da residência, considerando que justamente um dos aspectos mais importantes em relação à formação docente é proporcionar ao aluno de pedagogia oportunidades para que desenvolva a capacidade de relacionar teoria e prática docente (PANNUTI, 2015, p. 7).
\end{abstract}

Nesse sentido, teve-se como foco do trabalho identificar e analisar as primeiras ações, especificamente, aquelas desenvolvidas no primeiro semestre do programa. Destacamos que, no período supracitado as principais etapas da RP foram o Curso de Formação de preceptores e residentes; estudos teóricos e metodológicos; conhecimento da Base Nacional Comum Curricular (BNCC) e a ambientação na escola-campo, conhecendo os espaços escolares e construindo o plano de atividades. Assim, de acordo com Souza (2016, p. 11),

\footnotetext{
A teoria e prática, conhecimento e ação articulam-se na formação, portanto, devem ser inseparáveis, como devem ser inseparáveis as concepções e habilidades operativas, técnicas e tecnológicas no trabalho docente, o qual é desenvolvido diariamente na complexidade da sala de aula.
}

A partir das concepções levantadas sobre a Residência Pedagógica, seus objetivos e metas a serem concretizadas, esse trabalho realizou uma investigação a partir da opinião dos acadêmicos do curso de Licenciatura em Ciências Biológicas e Licenciatura Química do Instituto Federal Farroupilha, Campus São Vicente do Sul -RS, em relação as contribuições da RP em sua formação profissional. De acordo com as visões dos acadêmicos entrevistados serão trazidas reflexões e discussões que possam contribuir na formação de professores. 
Na próxima seção será discutida o desenvolvimento da pesquisa apresentada, estabelecendo a metodologia utilizada para entender os resultados e discussão dos mesmos.

\section{METODOLOGIA: a Residência Pedagógica no IFFar, Campus São Vicente do Sul}

O trabalho foi desenvolvido na perspectiva de uma abordagem quantiqualitativa. Na concepção de (Gerhardt; Silveira 2009), qualitativa é um tipo de pesquisa que se preocupa com representatividade número, e sim com o aprofundamento da compreensão de um grupo social, de uma organização, por exemplo. A abordagem qualitativa opõe-se ao pressuposto de um modelo único de pesquisa para todas as ciências, pois apresenta a capacidade de fazer a análise das narrativas, das quais não existe a possibilidade de mensurar numericamente.

Já a pesquisa quantitativa se dá pelo uso da quantificação, tanto na coleta quanto no tratamento das informações, se utiliza de técnicas estatísticas, objetivando resultados que evitem possíveis distorções de análise e interpretação, possibilitando maior margem de segurança, (DALFOVO et al. 2008). Desse modo, podemos nos apropriar dos dados e usá-los concomitantemente com a análise das respostas do instrumento de pesquisa.

Assim, neste trabalho, são utilizados os dois métodos de pesquisa para que as ideias expostas sejam complementadas através da quantificação e da preocupação nas ideias e concepções ofertadas pelo público alvo. O sentido desse trabalho preocupa-se com as considerações de um grupo fechado, buscando compreensão de aspectos da realidade. Para tanto, o sujeito está sendo enfatizado como meio de compreender e interpretar as experiências, analisando as informações narradas de forma organizada, no entanto intuitiva (GERHARDT; SILVEIRA 2009, p. 34).

O público-alvo para a pesquisa foram os alunos do curso de Licenciatura em Ciências Biológicas e Licenciatura em Química, ambos do Instituto Federal Farroupilha, Campus São Vicente do Sul (IFFar-SVS). Esses acadêmicos fazem parte do grupo Residência Pedagógica nessa Instituição desde o primeiro semestre do ano de 2018, ao total são 30 componentes. A pesquisa foi desenvolvida durante o mês de janeiro do ano 
de 2019. No sentido de manter o sigilo dos sujeitos participantes, estes serão nomeados de acordo com letra e número, por exemplo R1, R2, etc.

A coleta de dados ocorreu a partir de um questionário com perguntas direcionadas, apresentadas no Apêndice A que contemplaram reflexões sobre a importância do Programa de Residência Pedagógica para a formação docente, as respostas obtidas foram transcritas conforme os participantes responderam, sem quaisquer modificações. Para análise dos dados utilizou-se a Análise Textual Discursiva (MORAES; GALIAZZI 2006). Em conjunto com a revisão bibliográfica foi possível compreender as respostas obtidas, as mesmas podem ser observadas na seção de resultados e discussões.

\section{RESULTADOS e DISCUSSÃO}

A partir das perguntas utilizadas no questionário foi possível fazer um levantamento sobre as opiniões formadas pelos residentes no tempo em que ingressaram no Programa, traz relevância para uma visão concreta acerca da formação dos professores do IFFarSVS. As cinco questões propostas estarão sendo discutidas neste tópico e aliadas a ideias de autores que complementam com explicações necessárias.

A etapa inicial dos questionamentos estabelecidos foi a identificação dos entrevistados, dos 30 bolsistas $^{1}$, 21 indivíduos responderam, sendo 13 acadêmicos de Licenciatura em Ciências Biológicas e oito graduandos de Licenciatura em Química. Esta é uma importante característica da Residência Pedagógica no IFFar-SVS, em que os alunos trabalham de forma integrada possibilitando a troca de conhecimentos, experiências, e assim enriquecer seus aprendizados em diversos pontos de vista.

Inicialmente, tratou-se de investigar sobre a visão dos residentes sobre a importância do Programa Residência Pedagógica na sua formação docente. ao partir das respostas foi possível identificar que $76 \%$ relataram ser importante, $19 \%$ disseram ser imprescindível e apenas 5\% demonstraram ser dispensável. Pode-se perceber que a maioria dos envolvidos acreditam que o Programa corresponde a um complemento em sua formação acadêmica. A Residência Pedagógica para professores iniciantes é uma das

\footnotetext{
1 O questionário foi encaminhado para os 20 residentes, porém, não ocorreu o retorno de todos. 0 mesmo foi solicitado três vezes pelas pesquisadoras, mas não obtendo êxito.
} 
modalidades de formação continuada a "qual contribui significativamente para uma profissionalização docente e que deverá se tornar realidade no sistema educacional brasileiro" (SOUZA, 2016, p. 12).

Posteriormente, questionou-se a relação teoria e prática, o que é muito cobrado pelos estudantes, uma vez, que é uma forma efetiva de consolidar conhecimentos e conseguir estabelecer contato com a carreira escolhida. Para tanto, 90,5\% dos residentes concordou que o Programa é uma forma de unir teoria e prática durante o processo de graduação, no entanto, apenas 9,5\% não acreditam ser uma forma de trabalhar o conjunto de teorias e práticas.

Ressaltamos que esse Programa está na primeira edição, e foi implementado na Instituição com projeto/núcleo multidisciplinar único, ou seja, no IFFar a RP é desenvolvida apenas no campus São Vicente do Sul, devido aos requisitos de cumprimento do objeto, e principalmente, em relação as exigências quanto ao número mínimo de integrantes, dentre outras. Sabemos que, nos cursos de licenciatura a evasão é alta e o cumprimento de 30 integrantes em fase final de curso tornou-se um desafio para a implementação do referido programa.

Nesse sentido, Poladian (2014) discorre que, cada vez mais, argumenta-se sobre o papel fundamental que o exercício da profissão tem na construção de um conhecimento prático-profissional, que nem sempre está pronto nas teorias existentes, por exemplo, no caso da atuação docente, não basta conhecer muitas teorias para ser bom professor, é preciso saber quando utilizá-las, transformá-las constantemente para solucionar os problemas impostos cotidianamente na ação. Sobre a formação de professores Oliveira $e t$ al. (2019, p. 1) contribui salientando a importância na formação inicial,

Já que é durante a formação que o professor adquire boa bagagem teórica, para enriquecer os seus conhecimentos, construir seus próprios saberes e ser autor de sua profissão, buscando ser um profissional competente e de qualidade.

Prosseguindo as reflexões e análises das respostas apresentadas pelos residentes nos questionários, a terceira pergunta centrou-se no que diz respeito a Residência pedagógica possibilitar uma formação construtiva dos saberes da docência. Ressaltamos que consideramos importante realizar tal questionamento aos mesmos, visto que nesse momento os licenciandos buscam por experiências e competências que possam favorecer 
em sua formação. O resultado encontrado foi positivo, logo, 95\% dos entrevistados disseram ter possibilidade de construir saberes através do Programa, somente 5\% discordaram com essa ideia.

Esses dados condizem com a quarta pergunta, em que questiona se as experiências que os estudantes já adquiriram, nesse tempo que fazem parte do Programa, são úteis em sua formação. O resultado obtido, ou seja, 95\% concordam ser experiências úteis e 5\% falam não ser. A organização e legislação do Programa de RP, apresenta em sua proposta além da formação de professores o estreitamento de laços com as escolas de Educação Básica (BRASIL, 2018), oportunizando aos futuros professores ao ingressarem no exercício efetivo da docência, serem conscientes da realidade das escolas.

Por fim, a quinta e última questão é aberta e sugere reflexão ao propor que os residentes escrevessem uma frase que expressasse sua percepção sobre a Residência Pedagógica. Com as respostas obtidas encontramos algumas categorias "comuns" na visão dos residentes sobre a RP. As categorias emergentes nas respostas dessa questão são: (1) formação docente; (2) saberes docentes; (3) o trabalho em grupo. A seguir são apresentadas as categorias separadamente.

\section{1- Formação Docente}

Nesse primeiro bloco de respostas apresentados é marcante na escrita dos Residentes a importância da RP para sua formação profissional docente. A aproximação com o ambiente escolar, nas atividades propostas, possibilita uma formação além daquela oferecida durante o Curso de licenciatura, como é possível visualizar nas narrativas dos residentes.

\footnotetext{
“A RP contribui significativamente na formação profissional dos estudantes de licenciatura, pois dá a oportunidade do acadêmico de inserir no meio escolar, possibilitando uma troca de saberes" (R1)

"O programa significa para mim, uma oportunidade de formação profissional mais completa” (R5).

"Significa possibilitar aos estudantes de licenciatura discussões e dentro do âmbito de um programa que visa a formação de professores engajados com
} 
formação de alunos críticos e engajados com a sociedade em que estão inseridos" (R8).

"A RP significa para mim um aprendizado que não terei em aulas, descobrir mais sobre assuntos que temos em sala de aula que acabam passando batidos durante nossa formação” (R2).

Uma formação constante, não se restringe ao curso de licenciatura, especificamente à formação inicial, ou seja, parte-se do pressuposto de que além do ambiente de formação as vivências e trocas com os outros residentes, vão contribuir para a construção da identidade docente.

No entanto, a RP é um programa interligado com a formação inicial, que apresenta em seus objetivos e finalidades a contribuição para a formação docente. As quatrocentas e quarenta horas propostas no programa, vão dar a validade para os Estágios Curriculares, apresentados na Matriz de cada curso. Nesse sentido, a RP, também é vista pelos residentes como uma "forma diferenciada de cumprir os estágios obrigatórios". Pois, o envolvimento dos residentes nas escolas tem como objetivo a imersão e vivência direta na docência. Assim, o programa estimula, incentiva e motiva os residentes, ao estudo, desenvolvendo a formação cidadã, ao fortalecendo os cursos de licenciatura e ao desenvolvimento de saberes docente.

\section{2- Saberes Docentes}

A RP, em sua proposta apresenta e oportuniza aos residentes as trocas de vivências, experiências e saberes entre os preceptores e docente orientadora. Assim, entendemos que uma formação pautada pelo saber docentes e profissionais (TARDIF, 2014), exige tempo, designação e valorização profissional, bem como a associação de políticas educacionais, no caso a RP, ponderando o lócus de trabalho, o ambiente escolar, no qual está inserido o preceptor. Nesse sentido apresentamos algumas respostas dos residentes:

\footnotetext{
"O programa da Residência Pedagógica contribui no decorrer da formação pois há integração de saberes docentes, sendo que há troca de saberes com as preceptoras atuantes na docência, bem como com a coordenação do programa, possibilitando uma visão ampla da profissão, auxiliando na nossa busca pelo "ser professor" (R20).

“A residência propôs novos olhares acerca da docência, trazendo relatos de professoras mais experientes, onde somou muito neste primeiro semestre.
} 
Além das licenciaturas do campus estarem trabalhando juntas e pode-se ter um olhar mais critico sobre leituras propostas" (R18).

"A residência pedagógica nos proporciona a integração, assim evidenciando uma troca de conhecimentos e experiências, respeitando a posição do colega” (R4).

“Uma oportunidade de desenvolvimento pessoal e profissional” (R9)

"Adaptação a políticas públicas e uma tentativa de melhorar a qualificação profissional do professor” (R15).

Nesta categoria, destacamos a formação docente interligando saberes, na busca da identidade profissional. A contribuição dos relatos das "professoras mais experientes", além de propiciar o embate dialético entre ação-reflexão-ação, presente em suas vivências e práticas pedagógicas, oportunizou aos residentes uma aproximação crítica, reflexiva da realidade estudada e da organização da RP em grupos nas escolas-campo. Assim, Freire (1991, p. 81) aponta:

Será privilegiada a formação que se faz no âmbito da própria escola, com pequenos grupos de educadores ou com grupos ampliados, resultantes do agrupamento das escolas próximas. Este trabalho consiste no acompanhamento da ação-reflexão-ação dos educadores que atuam nas escolas; envolve a explicação e análise da prática pedagógica, levantamento de temas de análise da prática pedagógica que requerem considerando a reflexão sobre a prática e a reflexão teórica.

Desse modo, na perspectiva freireana, a formação de professores necessita ser capaz de provocar mudanças na educação, mais especificamente na sala de aula, na escolacampo. De maneira que consiga substituir a educação bancária, que há tempos tem sido praticada nos estabelecimentos escolares, por uma educação problematizadora que forme sujeitos capazes de fazer uma leitura crítica do mundo (FREIRE, 2011) para, então, transformá-lo. A formação de professores é o ponto central da RP, a qual necessita transpor as ações práticas e formais originadas nas políticas educacionais, bem como estar presente na inserção do cotidiano do exercício profissional e da prática escolar.

\subsection{Trabalho em grupo}

Nesta categoria, é destacado pelos residentes a importância do trabalho em grupo para possibilitar a troca de experiências e saberes. É possível observar que possuem 
satisfação e concordam com os objetivos propostos pelo Programa, dizendo ser uma forma de realçar e melhorar sua formação acadêmica, além de ser um espaço de discussão, construir, reconstruir conceitos e ideias. Também, deixam em evidência a importância da relação estabelecida entre os espaços escolares e professores envolvidos, intensificando o aprendizado, aprendendo o trabalho em grupo e respeitando as opiniões diferentes. Essas afirmativas, são corroboradas com as seguintes respostas:

\footnotetext{
"É uma experiência que nos possibilita trocar experiências com os colegas do curso de licenciatura em química, onde muitas vezes mesmo fazendo licenciatura esse convívio não existe" (R6).

"Para mim significa conhecimento e aprendizagem, além de trocas de experiências entre os envolvidos” (R17).

“A residência pedagógica é um programa que proporciona ser trabalhado teoria e prática de uma forma crítica" (R13).
}

Essa categoria apresenta respostas voltadas para as atividades realizadas em grupo, as trocas de experiências e a relação entre teoria e prática. Desse modo, propicia as interações e o desenvolvimento de situações de aprendizagem em conjunto, nos quais os residentes ministram atividades interligando seus saberes. Assim, o trabalho em grupo, torna-se mais significativo tanto para a ênfase pedagógica, como também para os vínculos afetivos estão diretamente relacionados, refletindo propriamente no trabalho dos residentes, das preceptoras, da docente orientadora. Enfim, nessa direção intensificando a formação enquanto docente, uma vez, que as experiências adquiridas preparam o futuro docente para os desafios que encontrará no ambiente escolar.

Os relatos mostram que os objetivos sustentados pelo Edital CAPES n ${ }^{\circ}$ 06/2018 que coloca em pauta a potencialização da formação inicial dos acadêmicos de licenciatura, interligar as Instituições de Ensino Superior com escolas de Educação Básica de forma a compartilhar conhecimentos, além de preparar os discentes para o real cenário educacional do Brasil, estão sendo alcançados efetivamente.

Segundo, Silva (2015), a partir da Residência Pedagógica, o licenciando torna-se parte da realidade escolar e não somente um espectador, trazendo voz e vez para suas concepções e experiências no cotidiano escolar, permitindo que os conhecimentos apreendidos nas salas das Instituições de Ensino Superior sejam colocados em prática. Assim, formação de professores deve protagonizar a responsabilidade que o professor 
possui, uma vez, que está envolvido em compartilhar informações com seus alunos e torná-lo agente ativo na transformação de sua realidade.

\section{CONSIDERAÇÕES FINAIS}

A formação de professores ganha enfoque em discussões que possam promover melhorias, dentre elas, existem políticas e programas que conseguem complementar e ofertar aos acadêmicos de licenciatura uma formação mais complexa. O Programa de Residência Pedagógica aponta, nas suas diretrizes, a possibilidade do residente se familiarizar de forma prática com a carreira escolhida, contribuindo para uma boa relação entre IES e escola de Educação Básica.

Desse modo, percebeu-se que os objetivos apontados pela CAPES estão sendo atingidos, uma vez observados, nas frases elaboradas pelos estudantes participantes do Programa, da mesma forma foi expressado o grande interesse dos bolsistas, os quais disseram que a Residência Pedagógica é uma parcela importante e imprescindível de sua formação. Pode-se, também, confirmar que a maioria dos residentes acreditam que é uma maneira de solidificar a teoria com a prática, sendo um fator determinante para uma formação com uma visão do real.

As experiências adquiridas no Programa Multidisciplinar de Residência Pedagógica/IFFar-SVS, de forma geral, foram significativas para grande parte dos entrevistados. No entanto, muitas experiências foram vivenciadas, pois o programa está na fase de finalização. As atividades desenvolvidas, as convivências com o grupo, com os professores orientadores, respaldam a aprendizagem e trocas de saberes, sendo, portanto, um caminho alternativo e enriquecedor para os conhecimentos além da graduação.

\section{REFERÊNCIAS}


BRASIL. Programa de Residência Pedagógica. 2018. Disponível em: $<$ http://www.capes.gov.br/educacao-basica/programa-residencia-pedagogica>. Acesso em: 12 jan. 2019.

CAPES. Edital CAPES no 06/2018 Programa de Residência Pedagógica. Chamada Pública para apresentação de propostas no âmbito do Programa de Residência Pedagógica. 2018. Disponível em: <https://www.capes.gov.br/images/stories/download/editais/01032018-Edital-6-2018Residencia-pedagogica.pdf >. Acesso em: 17 jan. 2019.

DALFOVO, M. et al. Métodos quantitativos e qualitativos: um resgate teórico. Revista Interdisciplinar Científica Aplicada. Blumenau, v.2, n.4, p.01-13, Sem II. 2008. ISSN 1980-7031.

FONTOURA, H. A. Formação de Professores para a Justiça Social: uma reflexão sobre a docência na Residência Pedagógica. Revista Ibero-Americana de Estudos em Educação. v.12, n.1, p. 120-133, 2017.

FREIRE, Paulo, A educação na cidade. São Paulo: Cortez Editora, 1991.

Paulo. A importância do ato de ler - em três artigos que se completam. 51. Ed. $2^{\mathrm{a}}$ reimpressão Cortez Editora. Perdizes. São Paulo, 2011.SP.

GERHARDT, T. E. e SILVEIRA, D. T. (org.). Métodos de Pesquisa. Universidade Aberta do Brasil - UAB/UFRGS e pelo Curso de Graduação Tecnológica, Planejamento e Gestão para o Desenvolvimento Rural da SEAD/UFRGS. Porto Alegre: Editora da UFRGS, 2009.

MOTA, A. S. et al. Residência Pedagógica: uma contribuição para a formação inicial de professores. VII Encontro das Licenciaturas. VII ENALIC. VI Seminário do PIBID. I Seminário do Residência Pedagógica. Fortaleza, CE. 2018.

OLIVEIRA, F. F. B. et al. A relação entre teoria e prática na formação inicial docente: percepções dos licenciandos de pedagogia. Disponível em: <http://www.editorarealize.com.br/revistas/fiped/trabalhos/Trabalho_Comunicacao_oral _idinscrito_45_817429beae1565e20c320420a758723d.pdf>. Acesso em: 17 jan. 2019.

PANNUTI, M. P. A relação teoria e prática na Residência Pedagógica. XII Congresso Nacional de Educação (EDUCERE). 2015. Disponível em: 
<http://educere.bruc.com.br/arquivo/pdf2015/15994_8118.pdf>. Acesso em: 12 jan. 2019.

POLADIAN, M. L. P. Estudo sobre o Programa de Residência Pedagógica da UNIFESP: uma aproximação entre Universidade e Escola na formação de professores. 2014. 130 p. Dissertação (Mestrado em Educação) -Pontifícia Universidade Católica de São Paulo, São Paulo, SP, 2014.

SILVA, K. G. Residência pedagógica: uma alternativa possível na formação inicial de professores de ciências e biologia na UFPR? Trabalho de Conclusão (Graduação de Ciências Biológicas-Universidade Federal do Paraná, Curitiba, PR, 2015.

SOUZA, F. D. (org.). Professores principiantes e a inserção à docência: contextos, programas e práticas formativas. Curitiba: Ed. UTFPR, 2016. 197 p.

TARDIF, M. Saberes docentes e formação profissional. $17^{\mathrm{a}}$ ed. Petrópolis: Vozes, 2014.

\section{APÊNDICE A}

Tabela 1 - Instrumento metodológico. Fonte: próprio autor.

Questionário sobre a importância do Programa de Residência Pedagógica na formação de professores no Instituto Federal Farroupilha, Campus São Vicente do Sul

1. Qual sua visão sobre a Residência Pedagógica na sua formação enquanto docente?

( ) Imprescindível

( ) Importante

( ) Dispensável

( ) Indiferente

2. Você acredita que a Residência Pedagógica é uma forma de unir teoria e prática durante a graduação?

( ) $\mathrm{Sim}$

( ) Não 
3. Você acredita que a Residência Pedagógica é um programa que possibilita uma formação construtiva dos saberes da docência?

( ) $\mathrm{Sim}$

( ) Não

4. As experiências que já foram obtidas por você nesse período que está compondo o Programa Residência Pedagógica Multidisciplinar - Licenciatura em Ciências Biológicas e Química - estão sendo úteis e fazendo a diferença na sua formação?

( ) $\mathrm{Sim}$

( ) Não

5. Faça uma descrição breve (1 frase), sobre o que a Residência Pedagógica significa na sua formação enquanto acadêmico de Licenciatura em Ciências Biológicas e Licenciatura em Química: 